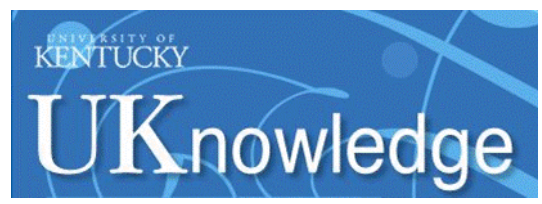

University of Kentucky

UKnowledge

\title{
The Effects of Stimulant Medication on the Online Story Narrations of Children with ADHD
}

\author{
Karen J. Derefinko \\ University of Kentucky, karen.derefinko@uky.edu \\ Ursula L. Bailey \\ University of Kentucky, ulbail2@uky.edu \\ Richard Milich \\ University of Kentucky, richard.milich@uky.edu \\ Elizabeth P. Lorch \\ University of Kentucky, elorch@uky.edu \\ Elizabeth Riley \\ University of Kentucky
}

Follow this and additional works at: https://uknowledge.uky.edu/psychology_facpub

Part of the Child Psychology Commons

Right click to open a feedback form in a new tab to let us know how this document benefits you.

\section{Repository Citation}

Derefinko, Karen J.; Bailey, Ursula L.; Milich, Richard; Lorch, Elizabeth P.; and Riley, Elizabeth, "The Effects of Stimulant Medication on the Online Story Narrations of Children with ADHD" (2009). Psychology Faculty Publications. 6.

https://uknowledge.uky.edu/psychology_facpub/6

This Article is brought to you for free and open access by the Psychology at UKnowledge. It has been accepted for inclusion in Psychology Faculty Publications by an authorized administrator of UKnowledge. For more information, please contact UKnowledge@lsv.uky.edu. 
The Effects of Stimulant Medication on the Online Story Narrations of Children with ADHD

Digital Object Identifier (DOI)

10.1007/s12310-009-9017-6 
Running head: ADHD MEDICATION

The Effects of Stimulant Medication on the Online Story Narrations of Children with ADHD 


\begin{abstract}
The current study investigated the inclusion of goal-based story events in the online story narrations of children with ADHD, as compared with their peers, and explored the effect of stimulant medication on the narrations in children with ADHD. Children completed a narration task on two separate occasions. Children with ADHD $(n=17)$ completed one narration on medication and the other one on placebo. Results indicated that narrations of comparison children $(n=25)$ were significantly more likely than narrations of children with ADHD to include the story's positive outcome, completion of the story's overall goal, and specific attempts linked to the goal. Children with ADHD included a larger total number of clauses in their narrations when on stimulant medication than when on placebo, but medication showed no significant effects for any other variables. Results indicate that stimulant medication may not be effective at reducing goal-based story comprehension deficits in children with ADHD.
\end{abstract}

Key words: ADHD, story comprehension, medication, goal structure 
The Effects of Stimulant Medication on the Online Story Narrations of Children with ADHD

It has been well established that children with attention deficit hyperactivity disorder (ADHD) experience significant and persistent academic difficulties (Loe \& Feldman, 2007; Rapport, Scanlan, \& Denney, 1999). In addition to the core characteristics of inattention and hyperactivity, fundamental deficits in higher-order processing skills have been suggested to be a major factor in poor scholastic performance in children with ADHD (Lorch, Milich, Astrin, \& Berthiaume, 2006; Lorch, Berthiaume, Milich, \& van den Broek, 2007; Reardon \& Naglieri, 1992). Although these deficits have been explored in a variety of ways (Carte, Nigg, \& Hinshaw, 1996; Kalff et al., 2003), tasks involving the comprehension of complex stories may offer a direct link between processing ability and academic performance. Story comprehension tasks make up a significant component of school performance (e.g., reading and writing tasks) and have been successfully employed to explore complex processing deficits in children with ADHD (Flory et al., 2006; Lorch, \& Berthiaume, 2005; Renz et al., 2003). However, despite advances in this area, relatively little is known about how stimulant medication, one of the primary treatment modalities for ADHD (Pelham, 2000), impacts higher-order processing skills involved in story comprehension. Although it has been demonstrated that stimulant medication is effective at improving attention and basic academic performance (DuPaul \& Eckert, 1997; Loe \& Feldman, 2007), it remains unclear whether stimulants improve the higher-order processing skills involved in online story narration.

\section{Story Comprehension and Narration}

Story comprehension is a set of higher-order processing abilities believed to develop early in life, simultaneously but independently from other reading skills (Kendeou et al., 2005). Effective story comprehension is believed to be a crucial component of successful academic performance due to the many complex skills involved, including interpretation of text/media, use of background information for interpretation, and the creation of a coherent mental representation (Trabasso, Secco, \& van den Broek, 1984). Without complex interpretive skills, basic language fails to achieve comprehension necessary for general academic success (Kendeou et al., 2005). 
In the story comprehension literature, many theories emphasize the importance of causal relations among story events (Ackerman, Silver, \& Glickman, 1990; Graesser \& Clark, 1985; Trabasso \& Nickels, 1992). Story grammar theory (Mandler \& Johnson, 1977) maintains that goal-attempt-outcome (GAO) sequences (where the character makes attempts at achieving an overall goal) are the most important idea units in a story and are more easily remembered than other aspects of the story (Mandler \& Johnson, 1977; Nezworski, Stein, \& Trabasso, 1982). The causal network model, (Trabasso \& Sperry, 1985; Trabasso \& van den Broek, 1985), an extension of the story grammar theory, suggests that recall depends upon the degree to which an idea unit is connected to other ideas in the story. Recall for an idea unit in a story increases with the number of causal connections it has (O’Brien \& Myers, 1987; Trabasso \& Sperry, 1985). Because goals generally have the highest number of causal connections, they are more easily recalled (Trabasso \& van den Broek, 1985), and are often considered reliable indicators of story comprehension.

There are several ways to assess story comprehension. Recall tasks allow researchers to explore comprehension through causal connections and goal plans, but are contingent on memory skills. In contrast, online (i.e., occurring during story processing) story narration, a narrative approach in which a child is asked to tell a story from a wordless picture book, allows for investigation of comprehension with reduced memory demands. As with recall tasks, successful online narration requires that the child understand the importance of a goal plan in resolving the dilemma in the story (Trabasso, Stein, Rodkin, Munger, \& Baughn, 1992), thereby providing a way to investigate deficits in story comprehension without memory or reading demands.

\section{Use of Online Narration Tasks in Children with ADHD}

Story narration tasks have recently been used in the ADHD literature to assess complex processing ability. Renz et al. (2003) employed an online story narration procedure to examine the use of goal structure among children with ADHD. The story used by Renz et al. (2003), Frog Where Are You? by Mercer Mayer (1969), contains 24 pictures and includes a hierarchical goal structure. Nine- to eleven-year old boys with and without ADHD were asked to tell a story based on the pictures, and these narratives were then coded using story grammar categories (Stein \& Glenn 1979), including overall goal, subsequent subgoal attempts 
and outcomes, and resolution of the overall goal. Results indicated that the two groups of children told stories of similar length. However, comparison children included the resolution of the overall goal significantly more often than children with ADHD, suggesting that comparison children are better able to maintain a goal plan throughout the narration of a story. Children with ADHD also used fewer specific goal-linked attempts than did comparison children. Based on these results, Renz et al. (2003) concluded that children with ADHD have a less developed understanding of goal plans than their peers.

Although the Renz et al. (2003) study is important to understanding the organization of narratives of children with ADHD, the age range of children within the study may not have captured major developmental changes in story narration. According to Trabasso et al. (1992), the most important ages for the development of the understanding of causal structure and goal plan are between three and nine. Thus, in a subsequent study (Flory et al. 2006), the methodology of Renz et al. (2003) was replicated using 7- to 9year-old boys and girls with and without ADHD. Similar to the results of Renz et al., the two groups of children did not differ in the lengths of stories they narrated. However, there were group differences on several of the story grammar categories related to the causal structure of the stories. Specifically, comparison children were significantly more likely to mention the initiating event, include Goal-AttemptOutcome (GAO) sequences in their narratives, and to state the completion of the overall goal than were the children with ADHD. Further, Flory and colleagues found that symptoms of inattention reached significance in accounting for observed group differences on five out of seven story coding categories, suggesting that this core characteristic of ADHD may account for differences in narrative performance (2006).

Using a slightly different design, Leonard, Lorch, Milich, and Hagans (2009) examined parentchild joint picture-book reading to examine parent and child storytelling and story comprehension in children with ADHD. Parents of 5 to 9 year-old ADHD and comparison children told their children a story based on a wordless picture-book, and children then retold the story to an examiner from memory. Results indicated that parents in both groups told stories of similar length and complexity and demonstrated similar affective and responsive quality when reading to their child. Further, the length of the child's retelling of the 
parent's story did not differ between groups. However, despite each parent's appropriate use of goal structure, children with ADHD included fewer goal-based events in their recall of stories, results that are consistent with the findings of Renz et al. (2003) and Flory et al. (2006).

The results of the Renz et al. (2003), Flory et al. (2006), and Leonard et al. (2009) story narration studies reveal problems that children with ADHD have in narrating a coherent, goal-based story. To create a coherent story representation, children need to recognize events that motivate the overall goal, actions and outcomes that result from the goal, and subgoals that may follow from actions and outcomes. The results of these studies point to goal-based story events as a major area in which children with ADHD are deficient in their story narrations. Further, these deficiencies in story representations are evident even when memory, attentional, and reading demands are relatively low, as is the case for online narrations.

It is important to note that these studies were designed to examine deficits in the complex skills involved with online story narration for children with ADHD, independent of medication. Because of this, children were required to be free of stimulant medication for at least 24 hours prior to participation in each of the aforementioned studies. Stimulant medication is acknowledged to be the most widely-used treatment for children with ADHD (Barkley, 2006). Given that deficits in online story narration among children with ADHD are well documented, it is important to examine how stimulant medication impacts story comprehension skills in children with ADHD.

Story Comprehension and Stimulant Medication

Given the frequency with which it is prescribed, stimulant medication in particular has been the topic of many studies investigating treatment efficacy in children with ADHD (Barkley, 2006; Loe \& Feldman, 2007). Although treatment studies have suggested that stimulant medication is successful in improving basic academic functioning, such as reducing disruptive behavior, increasing homework completion, and improving quiz grades (DuPaul \& Eckert, 1997; Loe \& Feldman, 2007), longitudinal research indicates that such treatment does not improve academic performance in the long-term (Barkley, 2006; Fabiano \& Pelham, 2002; Fischer, Barkley, Smallish, \& Fletcher, 2002; Hechtman \& Greenfield, 2003; LeFever, Villers, Morrow, \& Vaughn, 2002). It may be the case that stimulant medication treatment 
for ADHD, although effective in increasing attention and academic productivity, may not address higherorder story narration skills that are necessary for long-term academic success.

Only one study has examined the effects of stimulant medication on story comprehension performance. Francis, Fine, and Tannock (2001) asked 50 children with ADHD to retell stories from memory that they had previously heard via audiotape and seen as wordless picture books, both on and off stimulant medication. Although children showed some improvement in reporting on story character's internal responses and attempts when on medication, stimulants did not improve overall story recall length or accuracy of responses to comprehension questions (Francis et al., 2001). Thus, work by Francis and colleagues (2001) indicates that while stimulant medication appears to prime children with ADHD to perform short-term cognitive tasks by helping them focus and attend, it may not successfully improve higher-order abilities.

\section{The Current Study}

There are several reasons why it is important to study the impact of stimulant medication on story narration performance of children with ADHD. First, although initial work by Francis et al. (2001) suggested that stimulant medication increases attending to some aspects of a story, this study does not provide information on the impact of stimulant medication on online narration skills. This is an important issue because online story narration documents the process of building a story representation. Second, research on the impact of stimulant medication would benefit from the use of a comparison group of children without ADHD. Inclusion of this group allows documentation of the extent of deficits relative to comparison peers in the absence of medication. In addition, the use of a comparison group allows for the assessment of the degree to which medication may normalize the performance of the children with ADHD. Finally, although Francis et al. (2001) assessed some aspects of comprehension, goal-based categories were not included in analyses. Because goal-based attempts and outcomes are critical to recall and interpretation, the inclusion of these categories would provide additional understanding of crucial aspects of story comprehension skills (Trabasso \& Sperry, 1985; Trabasso \& van den Broek, 1985). In addition, goal-based categories are the areas where children with ADHD exhibit reliable deficits. 
The current study investigates group differences in the inclusion of goal-based story events in the online narrations of children with ADHD and comparison children, and explores the potential impact of stimulant medication on online narrations in children with ADHD. Children completed an online narration task on two separate occasions using two wordless picture books. Children with ADHD completed one of the narrations on medication and the other one on placebo, whereas the comparison children did the same two narrations without medication or placebo. Based upon the findings of Renz et al. (2003), Flory et al. (2006), and Leonard et al. (2009), it was hypothesized that unmedicated children with ADHD would evidence deficits in their narrations of goal-based events relative to their comparison peers. Further, and consistent with Francis et al. (2001), it was hypothesized that stimulant medication would improve basic aspects of performance, such as narration length. However, it is an open question whether medication would reduce deficits among children with ADHD in identifying important goal-based story events.

\section{Method}

\section{Participants}

A sample of 42 children (17 children with ADHD/combined type and 25 comparison children) participated in this study. The children in each group were between the ages of 9.0 and 13.8 years ( $M$ age $=11.6$ years, $S D=1.16$ ). Thirty-four of the children were Caucasian, 3 identified themselves as biracial, 5 identified themselves as African American, and 1 identified as Latina/o. In the ADHD group, 14 (82.4\%) of the children were male, and in the comparison group, $20(80.0 \%)$ were male. The children with ADHD were recruited from the Hyperactive Children's Clinic in the School of Medicine at the University of Kentucky. The children were carefully selected to fulfill the DSM-IV criteria for ADHD/combined subtype and to be free of confounding factors (i.e., low IQ, neurological problems). Diagnoses were based on a convergence of evidence from multiple measures and informants. Children who exhibited only attentional problems (i.e., the inattentive subtype) were not contacted for participation.

Children were first required to have received the appropriate DSM-IV (American Psychiatric Association, 1994) ADHD/Combined Type diagnosis based on a comprehensive psychiatric clinic evaluation at the Hyperactive Children's Clinic. This evaluation utilizes multiple assessment procedures 
designed to identify psychiatric and neurological factors that may influence or better account for ADHD symptoms, such as mood disorders, developmental disorders, epilepsy or neurological disorders, or mental retardation. In addition, the medical charts of all the children were reviewed in detail to gather specific information about ADHD diagnoses and medical history, including reason for clinic referral, age at onset of symptoms, classroom behavior via teacher ratings, evidence of impairment, parent ratings of behavior, IQ, medical history, and comorbid diagnoses. Children were not eligible for the study if their medical charts provided evidence of IQ scores lower than 80, presence of sensory impairments, diagnoses of epilepsy or other neurological disorders, or prescribed medication that could not be temporarily discontinued during study participation. Finally, children with ADHD were required to be prescribed a stimulant medication at the time of participation in the study. Children who were not prescribed stimulant medication were not eligible for the study.

If the above criteria were met, then a parent of the child with ADHD was contacted and invited to participate in the study. During the first testing session, a semi-structured interview, similar to the PChIPS (Weller, Weller, Fristad, Rooney, \& Schecter, 2000), but only consisting of verbatim DSM-IV criteria for ADHD and ODD, was conducted with the parent to confirm the child's diagnostic status. This interview also provided a common measure of ADHD symptoms for all children in the study, because the assessment measures used to make the initial clinic diagnosis varied. The interviews were conducted by trained psychology graduate students. In the interview, the parent was asked whether each diagnostic criterion was true of his/her child, and, if so, the parent was asked to give behavioral examples. If a behavior was characteristic of the child, the parent was additionally asked whether that behavior seemed inappropriate for the child's age and whether it impaired the child's functioning academically and/or socially. A diagnostic criterion was considered to be endorsed only if the parent indicated the behavior was age-inappropriate and impairing. This interview procedure has been used successfully by our research group in previous studies, with interrater reliabilities for the number of ADHD symptoms endorsed by the parent above $95 \%$ (Lorch et al. 1999). In addition to the information from the structured psychiatric interview, parents completed the Conners (1997) Parent Rating Scales (CPRS-R:S). To be 
placed in the ADHD group, children must have met criteria for this diagnosis on the structured interview, and have T scores above 60 on the Conners Hyperactivity scale and the ADHD Index.

The comparison group of children without ADHD was recruited through newspaper advertisements, posted advertisements in the community, and by word-of-mouth. They were screened during a recruitment phone call in which the parents were asked if their child had ever been referred for any behavioral or learning problems. The comparison children were not required to be symptom free, but had to have three or fewer symptoms in a diagnostic category. These children were significantly less symptomatic than the children with ADHD in terms of the DSM-IV criteria for inattentive, hyperactive, and oppositional symptoms, and moreover did not meet diagnostic criteria for any subtype of ADHD. In addition, the children in the comparison group had $\mathrm{T}$ scores below 60 on all of the Conners rating scales. As indicated in Table 1, the diagnostic interview and Conners rating scale data successfully differentiated between the comparison children and the ADHD group.

Among the seventeen children with ADHD, it was required that they were being treated with psychostimulant medication. Children with ADHD were being prescribed one of the following: methylphenidate hydrochloride ( $n=11$; dosage ranged from 18 to $54 \mathrm{mg}$ ), amphetamine/dextroamphetamine ( $n=3$; dosage ranged from 15 to $30 \mathrm{mg}$ ), methylphenidate transdermal system $(n=2$; dosage $=30 \mathrm{mg})$, and dexmethylphenidate hydrochloride $(n=1$; dosage $=30 \mathrm{mg})$. Participants who were receiving other medications that could not be easily withdrawn for testing (e.g., chlonidine) were not eligible for the study. All children received two small toys and $\$ 20.00$ for their participation in each session. Groups were not significantly different on the basis of age, gender, parental education, or racial composition.

\section{Procedure}

Children in both the ADHD and comparison groups attended two individual sessions, one for the narration of each story, which occurred at least 1 week apart. Story order was randomized prior to participation. For children with ADHD, medication/placebo days were randomly assigned prior to scheduling. Upon arrival, children and their parents were met by a trained graduate student for the intake 
interview. First, written consent was obtained from the parent and verbal assent was obtained from the child. Children over the age of 13 provided written assent in addition to the written consent obtained from the parent.

Parents of children with ADHD were then interviewed briefly about the child's medication and medication dosage. On medication days, children with ADHD were required to have taken their usual dose of stimulant medication at home 1 hour prior to participation. Due to the need for parents to administer medication to children, parents were not blind to medication status. Although children knew when they were taking their usual medication on medication days, they were unaware that they would be receiving a pill on placebo days, or what the pill contained. On placebo days, children with ADHD were required to have been off of all stimulant medication for 24 hours prior to participation. Upon confirmation from the parent that the child had not received medication within 24 hours, a small blue and white placebo pill was presented to the child's parent, who subsequently administered the placebo to the child. The parent and child were provided the following instructions: "This is something we are testing in our research. We know it is perfectly safe." Parents then instructed their child to swallow the pill with water provided. For children who were unable to swallow pills $(n=2)$, the placebo capsule was opened and contents were stirred into a small cup of water for administration. Due to randomization of medication and placebo conditions, all children were debriefed about the placebo medication after the second session of the study. Parents of comparison children were also interviewed briefly about any medication the child was prescribed to ensure that no medications that might impact performance were administered.

Upon completion of the intake interview, all children were met by a research assistant (either a trained graduate or undergraduate student) and were allowed to choose a small toy from a box. Research assistants who worked with children were blind to the child's diagnostic group and medication status. Children then were taken by the research assistant to a private testing room where they began the task. While they waited for their child to complete the task, parents completed the DSM-IV interview and Conners Parent Rating Scale with the trained graduate student while the child completed the study with 
the research assistant. During the second session, parents waited in the waiting room for the child to complete the study.

Two different stories were used for this task, both wordless picture books and both by Mercer Mayer. The first story, Frog Where Are You? by Mercer Mayer (1969), contains 24 pictures and includes a hierarchical goal structure. The story begins with a frog escaping from its owner, a little boy. The overall goal that can be inferred from the pictures is for the boy to find the frog and bring it back home. The story then progresses with a number of unsuccessful attempts to meet this goal, creating subgoals. Ultimately, the boy does find the frog, and to his surprise, the frog's family. The boy is then allowed to take a baby frog home, thus resolving his overall goal of bringing a frog back home.

The second story, A Boy, A Dog, and A Frog (Mayer, 1967), is the prequel to Frog Where Are You? and also contains a series of 24 pictures. In this story, a boy sees a frog while fishing with his dog, which is the initiating event that sets up the overall goal of trying to catch the frog for a pet. When the boy fails to catch the frog in his first attempt, this prompts further attempts (subgoals). After several more futile attempts to catch the frog, the boy gives up and walks home with his dog. The frog then appears to be lonely without the boy and follows the boy's footprints home. The frog eventually finds the boy taking a bath and jumps in, thus providing a positive resolution to the boy's overall goal of catching the frog as a pet.

Children were tested individually and were seated across from the research assistant. A binder containing one of the two stories, chosen randomly, was placed in front of the child and the research assistant said, "This is a book that tells a story. This story only has pictures. You have to make up the words for the story. Start with the first picture, and for each of the pictures, tell me the story. Make sure you make up a part of the story for each of the pictures in the book." The child then told the story to the research assistant, picture by picture. If any pictures were skipped, the research assistant pointed at the picture, saying "tell me about this picture." The child was given as much time as needed to complete the story and each narrative was audio and video recorded for later coding. 
Narratives were transcribed verbatim from the recordings. Two trained coders blind to the child's diagnosis and medication status parsed the narratives into discrete story units (i.e., single ideas or events from the story), which then were coded based on the story grammar categories designated by Mandler and Johnson (1977). Inter-rater reliability averaged above .80 across coding categories. Consistent with previous story narration studies (Flory et al., 2006; Renz et al., 2003), we examined story grammar categories directly related to the goal structure of the story, as well as narration errors and the total number of clauses.

Initiating event. The initiating event sets up the overarching goal of the main character. For instance, in Frog Where Are You?, the initiating event is when the boy finds that the frog has escaped from his jar, establishing the boy's goal of finding the frog and bringing it back home. This variable was coded as to whether the child did or did not mention the initiating event.

Attempts. In most stories, attempts to complete the goal generally follow statement of the initiating event. Two types of attempts were coded in the children's narratives. A linked attempt was coded if the child explained the boy's goal of trying to find/catch the frog (e.g., "The boy looks for the frog"). A specific linked attempt was coded if the child explained that the boy was searching or calling for or trying to catch the frog in a specific location (e.g., "The boy looked for the frog in the hole"). These two variables were each coded as the total number of attempts.

Outcomes. In both stories, most of the boy's attempts to find or catch the frog end in negative outcomes, as the boy repeatedly is unsuccessful at meeting his goal. This variable was coded as the total number of negative outcomes stated by the child. The final attempt to find or catch the frog in each story ends in a positive outcome. This variable was coded as to whether the child did (1) or did not (0) mention the final positive outcome.

Goal-attempt-outcome (GAO) sequences. Linked attempts followed by a positive or negative outcome constitute a GAO sequence. GAO sequences are vital to the story because they represent the essential elements of goal structure. Narratives that include many GAO sequences are generally more organized and cohesive than those with few sequences. This variable was coded as the total number of 
positive and negative outcomes.

Goal completion. One of the most important aspects of goal structure is generally found at the end of a story. Goal completion is the resolution to the overall goal of trying to find or catch the frog (e.g., "The boy got to keep one of the little frogs and bring it home"). This variable was coded as to whether the child did (1) or did not (0) state the completion of the overall goal.

Errors. Narratives also were coded for three different categories of errors. Within clause errors were coded when part of a child's clause was unclear or ambiguous, such as "The little boy looked there" ("there" does not refer to a specific location). A whole clause error was coded when a child stated an event that either did not occur in the story, or occurred in a different order than was stated. Repetition errors were coded when the child restated an idea from a previous picture when it was not occurring in the present picture. Due to the low frequency of whole clause and repetition errors, these categories were not included in analyses.

\section{Results}

The first set of analyses compared Session 1 and Session 2 narrations of the comparison children. Because there were no significant mean differences between the sessions, the average for each variable was calculated. These variables were used in the second set of analyses, which contrasted performance of the comparison children with performance of children with ADHD in the placebo condition. The third set of analyses compared the performance of the children with ADHD in the medical and placebo conditions. Based on previous research, medication effects were hypothesized to improve basic performance over the placebo condition. However, it was unknown whether medication would reduce deficits in identifying important goal-based events.

\section{Comparison of Diagnostic Groups on Story Narration Variables}

Group comparisons on story narration variables are presented in Table 2. Consistent with previous research, narrations of comparison children were significantly more likely to include the story's positive outcome, $t(40)=2.56, p<.01$, effect size $d=.82$, and completion of the story's overall goal, $t$ $(40)=2.16, p<.05, d=.67$ (see Table 1$)$. In addition, comparison children included more specific 
attempts linked to the goal than did children with ADHD, $t(40)=2.53, p<.01, d=.80$. Consistent with previous research, the narrations of the diagnostic groups did not differ in length, $t(40)=0.53, p>.10$, and no other variable showed significant diagnostic group differences. For those comparisons that were significant, effect sizes were all greater than .5, indicating large effects (Cohen, 1992).

\section{Comparison of Story Variables for Medication and Placebo Conditions}

Paired t-tests were used to examine medication vs. placebo conditions across story narration variables. Results indicate that compared to the placebo condition, medication had little impact on the narrations of children with ADHD. As shown in Table 3, children on medication included a larger total number of clauses in their narrations than when on placebo, $t(16)=1.80, p<.05, d=.90$. The presence of stimulant medication showed no significant effects for any other variables, including all of the goalbased categories.

\section{Discussion}

The current study examined group differences in the inclusion of goal-based story events in the online narrations of children with ADHD and comparison children, and explored the potential impact of stimulant medication on online narrations in children with ADHD. As predicted, narrations of comparison children were significantly more likely than narrations of children with ADHD to include goal-based story events. More specifically, comparison children were more likely to include the story's positive outcome (e.g., the boy's final and successful attempt to find or catch the frog), and completion of the story's overall goal (e.g., the resolution to the overall goal of trying to find or catch the frog). This suggests that children with ADHD have a specific deficit in their ability to complete or "wrap up" the story for the listener. Further, comparison children were more likely to include specific attempts linked to the goal, which are clauses that indicate the boy's attempts to complete the goal in a specific location. This indicates that children with ADHD have difficulty keeping the goal of the story active throughout their narrations, thereby limiting their ability to convey a consistent goal-structure to the listener. These results are consistent with previous results with children of slightly younger ages (Flory et al. 2006; Leonard et al., 2009; Renz et al. 2003). Given that by 9 to 11 years of age, typically developing children generally are able to produce 
coherent story representations by consistently reinstating the goal plan to tie together actions and events in the story (Trabasso \& Stein, 1997), it is noteworthy that children with ADHD still demonstrate deficits in these skills between the ages of 9 and 13 years.

It is also notable that in contrast to previous research (Flory et al. 2006; Renz et al. 2003), children with ADHD did not demonstrate significantly more within-clause errors (i.e., making ambiguous references throughout a story) than comparison children. It is possible that the somewhat older age of participants in the current study attenuated differences in this category as older children have increased referential communication and social perspective-taking skills (Chandler, Greenspan, \& Barenboim, 1974; Paulauskas \& Goodman Campbell 1979). Nevertheless, goal-based narration deficits continue to exist at these older ages, suggesting that there is something specific about this complex skill set that maturation does not rectify.

Due to the importance of story comprehension skills to successful academic performance, it is therefore necessary to begin to understand why children with ADHD continue to demonstrate deficits in this area even at older ages. At this point, several candidate explanations exist. First, it is possible that problems in sustaining attention contribute to story comprehension deficits in children with ADHD. While adequate performance in specific categories (initiating events, linked attempts, negative outcomes, goal-attempt outcomes, and within-clause errors) suggests successful attention to the details of a story, it is possible that inattention impacts children's ability to perform higher-order cognitive processes, such as those involved in maintaining goal-structure during narration. As attention to stimuli, details of the instructions, and ongoing storyline are required in the current task, small but significant lapses in attention could potentially contribute to aggregate errors in the more demanding story categories throughout narration. In support of an underlying deficit in attention, Flory et al. (2006) found that among many potential mediators, inattention (as measured by reaction time standard deviation and omission errors on a go/no-go task) accounted for the most variance between ADHD and goal-based story comprehension deficits.

In addition to inattention, working memory problems, a deficit commonly associated with ADHD (Denney \& Rapport, 2001; Nigg, 2001), seem to relate to problems in story comprehension and story recall. 
To narrate goal-based categories, children are required to keep the goal active throughout the story, and to be able to convey this active goal consistently to the listener. Working memory problems may therefore interfere with the ability of children with ADHD to keep the story goal active throughout narration.

As an alternative interpretation of findings, children with ADHD may show deficits in metacognitive skills important for story representation and comprehension. For example, Freer, Little, Metze, Milich and Lorch (2008, April) have found that when asked to make up a story children with ADHD were less likely than comparison children to include even one goal-attempt-outcome sequence in their stories. This interpretation also is consistent with findings that children with ADHD have greater difficulty understanding causal relations among story events, suggesting a more fragmented story representation. Further, children with ADHD have been found to have problems in other areas of story comprehension related to meta-cognitive skills, including inference making and comprehension monitoring (Berthiaume, Lorch, \& Milich, in press).

To the degree that story comprehension deficits are due to basic processes such as inattention and working memory problems, it would seem that treatment with stimulant medication, which increases focus and improves attention, might therefore decrease problems with goal-based story comprehension. Although stimulant medication is known to increase academic productivity and attentiveness in children with ADHD (DuPaul \& Eckert, 1997; Elliot et al., 1997), as well as performance on some tasks of executive functioning (Aman, Roberts, \& Pennington, 1998), it has not been effective at improving other higher-order processes, such as social information processing (King et al., 2009), suggesting that stimulants do not rectify all higher-order cognitive deficits. Findings from the current study suggest that medication does not improve goal-based story comprehension skills in meaningful ways. Although children on medication included a larger total number of clauses in their narrations than when on placebo, stimulant medication showed no significant effects for any other variables, including all of the goal-based categories. This suggests that the increase in performance provided by stimulant medication is not attenuating the higher-order metacognitive skill deficits such as elaboration or understanding of goal-structure.

There are several different possibilities for why this is the case. First, it is possible that story 
comprehension deficits are, in fact, associated with inattention and working memory deficits, but that stimulant medication is not capable of improving overall skill performance that requires development over time and experience. This is consistent with previous work by Pelham and colleagues (1990) who examined medication effects on performance of children with ADHD during baseball playing. Specifically, Pelham et al. found that although stimulant medication improved immediate attention during the games, it did not affect actual performance or skills (1990). Similarly, Abikoff et al. (2009) found that while methylphenidate improved aspects of organization, time management, and planning in children with ADHD, it did not eliminate deficits to the point of normalization. In fact, over $60 \%$ of participants continued to exhibit significant deficits in these areas while on medication (Abikoff et al., 2009). Thus, medication may be a necessary, but not sufficient method for improving complex skill performance.

If medication alone is not sufficient to improve story comprehension performance, it may be that combining this treatment with behavioral approaches would be more effective. This combined approach has been shown to increase benefits for children with ADHD in the realms of symptomatic improvements as well as increased academic productivity (Carlson, Pelham, Milich, \& Dixon, 1992). It is therefore possible that specific forms of behavioral programs, such as contingency programs designed to reward the generation of goal-directed story descriptions, would improve narration of goal-based story categories. The combination of treatments should therefore be investigated in future work to determine whether such an approach improves the meta-cognitive deficits shown by children with ADHD.

Further, behavioral treatment combined with focused academic assistance may provide benefits above and beyond those offered through medication, as they can be tailored to target areas where deficits lie. For example, Berthiaume (2006) has recommended the use of educational interventions that specifically target the meta-cognitive deficits shown by children with ADHD in their story comprehension and narration. Such remedial strategies can include study aids that highlight causal connections, as well as story mapping techniques that require the student to identify major story events to improve connecting events and solidifying the overall causal structure of a story.

\section{Limitations and Future Directions}


There are some potential limitations in the current study that deserve mention. First, despite significant findings, the number of participants in the current study was limited, suggesting that larger numbers of participants in future studies would be necessary to identify other potential effects. In addition, although the current study screened out children with ADHD who exhibited significant intellectual problems, no direct assessment of intelligence was conducted. It is possible that intelligence scores may have differed between the ADHD and comparison groups, and therefore may have contributed to group differences in online story narration. Thus, it would improve story comprehension research to include assessment of intelligence and learning ability concurrently with online narration ability so that these variables can be statistically examined. Like intelligence scores, it is also possible that other demographic variables, such as parental education and socioeconomic status, may also impact results due to differences in exposure to books and stories. Future studies would do well to include these other potential factors that may influence story narration.

Further, the design of the current study did not allow for direct manipulation of stimulant medication, either by type of medication or by dosage. This point is important, given that previous research suggests that laboratory-administration (such as MTA medication approaches) may increase the effectiveness of stimulant medication (Jensen et al., 2001). However, utilizing medications that were individually prescribed and indicated beneficial to the children who participated allowed for naturalistic investigation of diverse medication strategies. It is the norm, rather than the exception, that children with ADHD are prescribed a variety of stimulant medications at various dosages. The current study allowed exploration of stimulant medication benefits as they are prescribed.

It should also be noted that although the research assistant who worked with the child on the story comprehension task was blind to medication condition, children with ADHD recognized that they were being administered a pill that was not their normal medication, which may have altered their performance in some way. However, studies with children using placebo-control designs suggest that children do not demonstrate a significant placebo effect (Pelham, Hoza, Kipp, Gnagy, \& Trane, 1997), indicating that it was unlikely that placebo impacted performance on the task in significant ways. 
Finally, as it remains unclear how goal-based story comprehension deficits relate to other dimensions of ADHD, future work would do well to employ research designs that directly explore this issue. Flory and colleagues (2006) were able to employ several measures to identify potential mediators in the relation between story comprehension and ADHD; it is possible that other tasks designed to assess these deficit areas may further illuminate the processes that underlie story comprehension deficits.

This study explored group differences in the inclusion of goal-based story events in the narrations of children with ADHD and comparison children, and investigated the effect of stimulant medication on online narrations in children with ADHD. Consistent with previous research, children with ADHD demonstrated deficits in their ability to narrate goal-based categories. Further, although stimulant medication improved the length of narrations, it did not improve performance on goal-based categories. Although research has begun to identify several candidate explanations for story-comprehension deficits, it appears as though stimulant medication alone is not sufficient for reducing story-comprehension deficits in children with ADHD. To reduce deficits in this important area of learning, future work should consider treatment methods for children with ADHD that directly address story goal-structure. 


\section{References}

Abikoff, H., Nissley-Tsiopinis, J., Gallagher, R., Zambenedetti, M., Seyffert, M., Boorady, R., \& McCarthy, J. (2009). Effects of MPH-OROS on the organizational, time management, and planning behaviors of children with ADHD. Journal of the American Academy of Child and Adolescent Psychiatry, 48, 166-175.

Ackerman, B. P., Silver, D., \& Glickman, I. (1990). Concept availability in the causal inferences by children and adults. Child Development, 61, 230-246.

Aman, C. J., Roberts, R. J., Jr., \& Pennington, B. F. (1998). A neuropsychological examination of the underlying deficit in attention deficit hyperactivity disorder: Frontal lobe versus right parietal lobe theories. Developmental Psychology, 34, 956-969.

American Psychiatric Association. (1994). Diagnostic and statistical manual of mental disorders (4th ed.). Washington, DC: Author.

Barkley, R. A. (2006). Attention-deficit hyperactivity disorder, 3rd ed.: A handbook for diagnosis and treatment. New York, NY: Guilford Press.

Berthiaume, K. S. (2006). Story comprehension and academic deficits in children with attention deficit hyperactivity disorder: What is the connection? School Psychology Review, 35, 309-323.

Berthiaume, K.S., Lorch, E.P., \& Milich, R. (in press). Getting clued in: Inferential processing and comprehension monitoring among boys with ADHD. Journal of Attention Disorders.

Carlson, C. L., Pelham, W. E., Milich, R., \& Dixon, J. (1992). Single and combined effects of methylphenidate and behavior therapy on the classroom performance of children with attentiondeficit hyperactivity disorder. Journal of Abnormal Child Psychology, 20, 213-232.

Carte, E. T., Nigg, J. T., \& Hinshaw, S. P. (1996). Neuropsychological functioning, motor speed, and language processing in boys with and without ADHD. Journal of Abnormal Child Psychology, $24,481-498$.

Chandler, M., Greenspan, S., \& Barenboim, C. (1974). Assessment and training of role-taking and referential communication skills in institutionalized emotionally disturbed children. 
Developmental Psychology, 10, 546-553.

Cohen, J. (1992). A power primer. Psychological Bulletin, 112, 155-159.

Conners, C. K. (1997) Conners' Rating Scales-Revised: Technical Manual. North Tonawanda, New York: Multi-Health Systems.

Denney, C. B., \& Rapport, M. D. (2001). Cognitive pharmacology of stimulants in children with ADHD. In M. V. Solanto, A. F. T. Arnsten, \& F. X. Castellanos (Eds.), Stimulant drugs and ADHD: Basic and clinical neuroscience. (pp. 283-302). New York, NY: Oxford University Press.

DuPaul, G. J., \& Eckert, T. L. (1997). The effects of school-based interventions for attention deficit hyperactivity disorder: A meta-analysis. School Psychology Review, 26, 5-27.

Elliot, R. Sahakian, B. J., Matthews, K., Bannerjea, A., Rimmer, J., \& Robbins, T. W., (1997). Effects of methylphenidate on special working memory and planning in healthy young adults. Psychopharmacology, 131, 196-206.

Fabiano, G. A., \& Pelham, W. E. (2002). Measuring impairment in children with attention-deficit hyperactivity disorder. ADHD Report 10, 6-10.

Fischer, M., Barkley, R. A., Smallish, L., \& Fletcher, K. (2002). Young adult follow-up of hyperactive children: Self-reported psychiatric disorders, comorbidity, and the role of childhood conduct problems and teen CD. Journal of Abnormal Child Psychology, 30, 463-475.

Flory, K., Milich, R., Lorch, E. P., Hayden, A. N., Strange, C., \& Welsh, R. (2006). Online story comprehension among children with ADHD: Which core deficits are involved? Journal of Abnormal Child Psychology, 34, 853-865.

Francis, S., Fine, J., \& Tannock, R. (2001). Methylphenidate selectively improves storyretelling in children with attention deficit hyperactivity disorder. Journal of Child and Adolescent Psychopharmacology, 11, 217-228. 
Freer, B., Little, S., Metze, A., Milich, R., \& Lorch, E. P. (2008, April). The Effectiveness Formulating a Story Representation among Children with Attention Deficit Hyperactivity Disorder and Comparison Children. Poster presented at the Twentieth Biennial Conference on Human Development, Indianpolis, IN.

Graesser, A. C., \& Clark, L. F. (1985). Structures and procedures of implicit knowledge. Norwood, NJ: Ablex.

Hechtman, L., \& Greenfield, B. (2003). Long-term use of stimulants in children with attention deficit hyperactivity disorder: Safety, efficacy, and long-term outcome. Paediatric Drugs 5, 787-794.

Jensen, P. S., Hinshaw, S. P., Swanson, J. M., Greenhill, L. L., Conners, C. K., Arnold, L. E., et al. (2001). Findings from the NIMH Multimodal Treatment Study of ADHD (MTA): Implications and applications for primary care providers. Journal of Developmental and Behavioral Pediatrics, 22, 60-73.

Kalff, A. C., de-Sonnevile, L. M. J., Hurks, P. P. M., Hendriksen, J. G. M., Kroes, M., Feron, F. J. M., Stevaert, J., van Zeben, T. M. C. B., Vles, J. S. H., \& Jolles, J. (2003). Low- and high-level controlled processing in executive motor control tasks in 5-6-year-old children at risk of ADHD. Journal of Child Psychology and Psychiatry, 44, 1049-1057.

Kendeou, P., Lynch, J. S., van den Broek, P., Espin, C., White, M., \& Kremer, K. E. (2005). Developing successful readers: Building early comprehension skills through television viewing and listening, Early Childhood Education Journal, 33, 91-98.

King, S., Waschbusch, D. A., Pelham, W. E., Frankland, B. W., Andrade, B. F. Jacques, S., et al. (2009). Social information processing in elementary-school aged children with ADHD: Medication effects and comparisons with typical children. Journal of Abnormal Child Psychology, 37, 579589.

LeFever, G. B., Villers, M. S., Morrow, A. L., \& Vaughn, E. S. (2002). Parental perceptions of adverse educational outcomes among children diagnosed and treated for ADHD: A call for improved school/provider collaboration. Psychology in the Schools, 39, 63-71. 
Leonard, M. A., Lorch, E. P., Milich, R., \& Hagans, N. (2009). Parent--child joint picture-book reading among children with ADHD. Journal of Attention Disorders, 12, 361-371.

Loe, I. M., \& Feldman, H. M. (2007). Academic and educational outcomes of children with ADHD. Journal of Pediatric Psychology, 36, 643-654.

Lorch, E. P., Berthiaume, K., Milich, R., \& van den Broek, P. (2007). Story comprehension impairments in children with ADHD. In K. Cain \& J. Oakhill (Eds.), Cognitive bases of children's language comprehension difficulties (pp. 128-155). New York: Guilford.

Lorch, E. P., Eastham, D., Milich, R., Lemberger, C. C., Sanchez, R. P., Welsh, R., \& Van den Broek, P. (2004). Difficulties in comprehending causal relations among children with ADHD: The role of cognitive engagement. Journal of Abnormal Psychology, 113, 56-63.

Lorch, E. P., Milich, R., Astrin, C. C., \& Berthiaume, K. (2006). Cognitive engagement in typically developing children and children with ADHD from preschool through elementary school. Developmental Psychology, 42, 1206-1219.

Lorch, E. P., Sanchez, R. P., van den Broek, P., Milich, R., Murphy, E. L., Lorch, R. F., \& Welsh, R. (1999). The relation of story structure properties to recall of television stories in young children with attention-deficit hyperactivity disorder and nonreferred peers. Journal of Abnormal Child Psychology, 27, 293-309.

Mandler, J. M., \& Johnson, N. S. (1977). Remembrance of things parsed: story structure and recall. Cognitive Psychology, 9, 111-151.

Mayer, M. (1967). A boy, a dog, and a frog. New York: Dial.

Mayer, M. (1969). Frog, where are you? New York: Dial.

Nezworski, T., Stein, N. L., \& Trabasso, T. (1982). Story structure versus content in children's recall. Journal of Verbal Learning and Verbal Behavior, 21, 196-206.

Nigg, J. T. (2001). Is ADHD a disinhibitory disorder? Psychological Bulletin, 127, 571-598.

O’Brien, E. J., \& Myers, J. L. (1987). The role of causal connections in the retrieval of text. Memory and Cognition, 15, 419-427. 
Paulauskas, S. L., \& Goodman Campbell, S. B. (1979). Social perspective-taking and teacher ratings of peer interaction in hyperactive boys. Journal of Abnormal Child Psychology, 7, 483-493.

Pelham, W. E. (2000). Stimulants. In A. E. Kazdin (Ed), Encyclopedia of psychology, Vol. $7 . \quad$ (pp. 474-476). New York, NY: Oxford University Press, New York, NY.

Pelham, W. E., Hoza, B., Kipp, H. L., Gnagy, E. M., \& Trane, S. T. (1997). Effects of methylphenidate and expectancy on ADHD children's performance, self-evaluations, persistence, and attributions on a cognitive task. Experimental \& Clinical Psychopharmacology 5, 3-13.

Pelham, W. E., McBurnett, K., Harper, G. W., Milich, R., Murphy, D. A., Clinton, J., \& Thiele, C.. (1990). Methylphenidate and baseball playing in ADHD children: Who's on first? Journal of Consulting and Clinical Psychology, 58, 130-133.

Rapport, M. D., Scanlan, S. W., \& Denney, C. B. (1999). Attention-deficit/hyperactivity disorder and scholastic achievement: A model of dual developmental pathways. Journal of Child Psychology and Psychiatry, 40, 1169-1183.

Reardon, S. M., \& Naglieri, J. A. (1992). PASS cognitive processing characteristics of normal and ADHD males. Journal of School Psychology, 30, 151-163.

Renz, K., Lorch, E. P., Milich, R., Lemberger, C., Bodner, A., \& Welsh, R. (2003). Online story representation in boys with attention deficit hyperactivity disorder. Journal of Abnormal Child Psychology, 31, 93-104.

Stein, N. L., \& Glenn, C. G. (1979). An analysis of story comprehension in elementary school children. In R. Freedble (Ed.), Multidisciplinary Approaches to Discourse Comprehension. Hillsdale, N.J.: Lawrence Erlbaun Associates.

Trabasso, T., \& Nickels, M. (1992). The development of goal plans of action in the narration of a picture story. Discourse Processes, 15, 249-275.

Trabasso, T., Secco, T., \& van den Broek, P. W. (1984). Causal cohesion and story coherence. In H. Mandler, N. L. Stein, \& Trabasso (Eds.), Learning and comprehension of text (pp. 83-111). Hillsdale, New Jersey: Erlbaum. 
Trabasso, T., \& Sperry, L. L. (1985). Causal relatedness and importance of story events. Journal of Memory and Learning, 24, 595-611.

Trabasso, T., \& Stein, N. L. (1997). Narrating, representing and remembering event sequences. In P. W. van den Broek, P. J. Bauer, \& T. Bourg (Eds.), Developmental spans in event comprehension and representation: Bridging fictional and actual events. (pp. 237-270). Mahwah, NJ: Erlbaum.

Trabasso, T., Stein, N. L., Rodkin, P. C., Munger, M. P., \& Baughn, C. R. (1992). Knowledge of goals and plans in the online narration of events. Cognitive Development, 7, 133-170.

Trabasso, T., \& van den Broek, P. (1985). Causal thinking and the representation of narrative events. Journal of Memory and Language, 24, 612-630.

Weller, E. B., Weller, R. A., Fristad, M. A., Rooney, M. T., \& Schecter, J. (2000). Children's Interview for Psychiatric Syndromes - Parent Version (PChIPS). Journal of the American Academy of Child and Adolescent Psychiatry, 39, 76-84. 
Table 1

Descriptive and diagnostic information by group

\begin{tabular}{lcccc} 
& Comp $(n=25)$ & ADHD $(n=17)$ & & \\
Variable & $M(S D)$ & $M(S D)$ & $F$ & $X^{2}$ \\
\hline Age (months) & $137.32(12.53)$ & $141.47(15.82)$ & .897 & .349 \\
Gender $(\%$ male) & 80 & 82.4 & .04 & .849 \\
Race $(\%$ white) & 80 & 82.3 & .04 & .849 \\
Mother's education (years) & $17.00(2.04)$ & $16.00(1.97)$ & 2.50 & .122 \\
Father's education (years) & $16.09(1.95)$ & $15.07(3.03)$ & 1.57 & .219 \\
DSM-IV Attention & $.48(.87)$ & $7.53(1.50)$ & 369.24 & .000 \\
DSM-IV Hyperactivity & $.64(.99)$ & $5.65(2.74)$ & 76.65 & .000 \\
DSM-IV Oppositional/Defiant & $.28(.68)$ & $3.18(2.53)$ & 29.92 & .000 \\
Connors Cognitive Problems/Inattention & $44.60(3.72)$ & $70.22(9.38)$ & 144.23 & .000 \\
Connors Hyperactivity & $46.56(3.94)$ & $73.35(12.01)$ & 106.98 & .000 \\
Connors ADHD Total & $44.68(4.03)$ & $73.71(6.67)$ & 309.74 & .000 \\
Connors Oppositionality & $44.04(5.14)$ & $60.12(13.62)$ & 29.04 & .000
\end{tabular}


Table 2

Means for the Two Diagnostic Groups on Relevant Story Variables

\begin{tabular}{|c|c|c|c|}
\hline & Comp $(n=25)$ & $\operatorname{ADHD}(n=17)$ & \\
\hline Story Variable & $M(S D)$ & $M(S D)$ & $t(40)$ \\
\hline
\end{tabular}

\section{Goal-Based Categories}

Initiating event $88.0 \%(21.8)$

$88.2 \%(33.2)$

$<1$

Linked attempts

$2.74(2.87)$

$2.11(1.32)$

$<1$

Specific linked attempts

$2.96(1.07)$

$1.76(1.98)$

$2.53 * *$

Negative outcomes

$2.30(0.90)$

$2.41(0.87)$

$<1$

Positive outcome

$96.0 \%(13.8)$

$70.6 \%(46.9)$

$2.56 * *$

Goal completion

$84.0 \%(23.8)$

$58.8 \%(50.7)$

$2.16^{*}$

Goal-Attempt-Outcome sequences

$3.42(1.04)$

$3.12(0.99)$

$<1$

Other Categories

Within-clause errors

4.06 (4.66)

$5.24(5.70)$

$<1$

Total number of clauses

49.88 (17.23)

46.94 (18.48)

$<1$

Note. $* p<.05, * * p<.01$ (one-tailed $t$-tests). Comp = comparison group (averaged across two sessions); $\mathrm{ADHD}=$ attention deficit hyperactivity disorder (placebo condition only). 
Table 3

Means for Children with ADHD in the Medication and Placebo Conditions

$$
\text { Medication Placebo }
$$

Story Variable

$M(S D)$

$M(S D)$

$t(16)$

\section{Goal-Based Categories}

Initiating event

$100.0 \%(0.00)$

$88.2 \%(33.2)$

1.46

Linked attempts

$2.76(1.35)$

$2.11(1.32)$

1.30

Specific linked attempts

$3.12(2.32)$

$1.76(1.98)$

1.56

Negative outcomes

$2.06(1.03)$

$2.41(0.87)$

$<1$

Positive outcome

$64.7 \%(49.3)$

$70.6 \%(46.9)$

$<1$

Goal completion

$76.5 \%(43.7)$

$58.8 \%(50.7)$

1.00

Goal-Attempt-Outcome sequences

$2.82(1.01)$

$3.12(0.99)$

$<1$

Other Categories

Within-clause errors

$6.35(6.43)$

$5.24(5.70)$

$<1$

Total number of clauses

$57.82(25.11)$

46.94 (18.48)

$1.80 *$

Note. $* p<.05$ (one-tailed $t$-tests). 